San Jose State University

SJSU ScholarWorks

Faculty Publications, Chemistry

Chemistry

$1-1-2008$

\title{
Favourable Influence of Hydrophobic Surfaces on Protein Structure in Porous Organically-Modified Silica Glasses
}

\author{
Daryl K. Eggers \\ San Jose State University, daryl.eggers@sjsu.edu \\ B. Menaa \\ San José State University \\ M. Herrero \\ Universidad de Salamanca \\ V. Rives \\ Universidad de Salamanca \\ M. Lavrenko \\ San José State University
}

Follow this and additional works at: https://scholarworks.sjsu.edu/chem_pub

Part of the Biochemistry Commons, and the Other Chemistry Commons

\section{Recommended Citation}

Daryl K. Eggers, B. Menaa, M. Herrero, V. Rives, and M. Lavrenko. "Favourable Influence of Hydrophobic Surfaces on Protein Structure in Porous Organically-Modified Silica Glasses" Biomaterials (2008):

2710-2718. https://doi.org/10.1016/j.biomaterials.2008.02.026

This Article is brought to you for free and open access by the Chemistry at SJSU ScholarWorks. It has been accepted for inclusion in Faculty Publications, Chemistry by an authorized administrator of SJSU ScholarWorks. For more information, please contact scholarworks@sjsu.edu. 


\title{
Favourable influence of hydrophobic surfaces on protein structure in porous organically-modified silica glasses
}

\author{
Bouzid Menaa $^{\mathrm{a}, *}$, Mar Herrero ${ }^{\mathrm{b}}$, Vicente Rives ${ }^{\mathrm{b}}$, Mayya Lavrenko ${ }^{\mathrm{a}}$, Daryl K. Eggers ${ }^{\mathrm{a}, *}$ \\ a Department of Chemistry, San José State University, San José, CA 95192-0101, USA \\ ${ }^{\mathrm{b}}$ Departamento de Química Inorgánica, Universidad de Salamanca, 37008 Salamanca, Spain
}

\section{A R T I C L E I N F O}

Article history:

Received 18 December 2007

Accepted 28 February 2008

Available online $\mathrm{xxx}$

\section{Keywords:}

Sol-gel encapsulation

Circular dichroism

Hydrophobicity

Protein stability

Molecular confinement

Surface morphology

\begin{abstract}
A B S T R A C T
Organically-modified siloxanes were used as host materials to examine the influence of surface chemistry on protein conformation in a crowded environment. The sol-gel materials were prepared from tetramethoxysilane and a series of monosubstituted alkoxysilanes, $\mathrm{RSi}\left(\mathrm{OR}^{\prime}\right)_{3}$, featuring alkyl groups of increasing chain length in the R-position. Using circular dichroism spectroscopy in the far-UV region, apomyoglobin was found to transit from an unfolded state to a native-like helical state as the content of the hydrophobic precursor increased from 0 to $15 \%$. At a fixed molar content of $5 \% \mathrm{RSi}\left(\mathrm{OR}^{\prime}\right)_{3}$, the helical structure of apomyoglobin increased with the chain length of the R-group, i.e. methyl $<$ ethyl $<$ $n$-propyl $<n$-butyl $<n$-hexyl. This trend also was observed for the tertiary structure of ribonuclease $A$, suggesting that protein folding and biological activity are sensitive to the hydrophilic/hydrophobic balance of neighboring surfaces. The observed changes in protein structure did not correlate with total surface area or the average pore size of the modified glasses, but scanning electron microscopy images revealed an interesting relationship between surface morphology and alkyl chain length. The unexpected benefit of incorporating a low content of hydrophobic groups into a hydrophilic surface may lead to materials with improved biocompatibility for use in biosensors and implanted devices.
\end{abstract}

(c) 2008 Elsevier Ltd. All rights reserved.

\section{Introduction}

In the past few years, numerous silica- and/or porous siloxanebased organic-inorganic materials have been employed to produce protein-doped hybrid materials as biosensors and as heterogeneous catalysts for industrial applications [1-6]. In particular, the design of organically-modified hydrophobic glasses for encapsulating lipases, a class of enzymes that mediate lipid reactions and function naturally at hydrophobic interfaces, has received much attention due to the potential application of these enzymes in the conversion of fats and oils to other products of value [7-18].

It is understood that protein function is dependent on proper folding of the polypeptide chain into a specific, three-dimensional structure and that protein structure, in turn, may be affected by its immediate surroundings [19-21]. Thus, in the crowded environment of a silica matrix, the physical and chemical properties of the glass are expected to influence protein structure and activity. This hypothesis may be tested by encapsulating proteins into chemically-modified silica networks and by monitoring slight alterations in protein conformation by spectroscopic techniques. Even though

\footnotetext{
* Corresponding author. Tel.: +1 408924 4960; fax: +1 4089244945.

E-mail addresses: bouzid.menaa@gmail.com (B. Menaa), deggers@science. sjsu.edu (D.K. Eggers).
}

many reports indicate that sol-gel glass encapsulation retains the activity of a wide variety of enzymes, as reviewed in Refs. [1-6], few of these reports attempt to quantify the fraction of properlyfolded protein, and the specific enzyme activities (normalized per mass of protein) are often omitted. Also, in the case of encapsulated enzymes, activity measurements may be influenced by multiple factors; diffusion of substrates into the pores, accessibility of enzyme molecules, and the adsorption of substrates to the silica surface, in addition to changes in protein structure, may reduce enzyme activity relative to the activity measured in bulk solution. Thus, the prevalence of unfolded or partially-unfolded proteins in sol-gel materials, as well as the contribution of unfolded proteins to lower specific enzyme activity, is hard to discern from the current literature.

We have reported previously that apomyoglobin, a protein of moderate stability in solution, becomes largely unfolded following glass encapsulation using a sol-gel protocol adopted by many investigators [22-24]. A change in protein conformation following glass entrapment also has been detected by other researchers $[25,26]$. Consequently, surface effects on protein structure are a genuine concern for encapsulation studies and for the field of biomaterials, in general. A careful examination of the relationship between protein structure and the physical properties of the host material may be critical for improving current applications and for the 
development of new biocompatible materials [6,27]. At the same time, such research may enrich our understanding of the biophysical forces that govern the protein folding-unfolding process, an important topic in the biomedical sciences because several human diseases are associated with misfolding of specific proteins [28].

With these issues in mind, organic-inorganic hybrid porous silica-based materials may constitute an ideal system for delineating the effects of surface chemistry on protein structure in crowded environments, including the crowded cytoplasm of a living cell [29]. Due to the large variety of commercially available, organicallysubstituted silane reagents, wet-aged-based silica glasses can be used as host materials for examining the structure and stability of a protein as a function of many variable glass properties (porosity, surface chemistry, surface area, etc.). Typically, these host materials are synthesized via the sol-gel technique, a method involving hydrolysis and polycondensation reactions with alkoxysilane precursors such as tetramethoxysilane (TMOS) or mixtures of TMOS and monosubstituted reagents, $\mathrm{RSi}\left(\mathrm{OR}^{\prime}\right)_{3}$ [30]. This approach is compatible with protein encapsulation because the process can be performed under mild conditions of temperature and $\mathrm{pH}$, avoiding irreversible denaturation of the protein. Moreover, the resulting, optically transparent glass materials facilitate the use of spectroscopic techniques for examining protein structure. In this regard, circular dichroism (CD) spectroscopy has been demonstrated to be a particularly useful tool for detecting modest changes in conformation of glass-encapsulated proteins relative to their conformation in dilute solutions [22-24,31,32]. Although CD measurements may be considered less sensitive than fluorescence techniques and may require more protein per experiment, the average global structure of the protein may be monitored by CD; in the far-UV region, the entire protein serves as the chromophore due to the differential absorbance of left-handed and right-handed circularly polarized light by the peptide units that define the backbone [33,34].

Here we report on the conformation and stability of two model proteins, apomyoglobin and ribonuclease $\mathrm{A}$, as a function of glass hydrophobicity. The secondary structure of apomyoglobin (apoMb) has been shown previously to be highly sensitive to changes in glass composition by far-UV CD [24], whereas ribonuclease A (RNase A) provides a means of checking the tertiary structure of a protein by $C D$ analysis in the near-UV region. The structural behaviour of each protein is examined in TMOS-derived silica glasses and in organically-modified glasses made from a series of alkyltrimethoxysilanes (methyl, ethyl, $n$-propyl, $n$-butyl, and $n$-hexyl) at different contents of the modifying precursor $(0,5,10,15 \%)$. The physical properties of the host silica matrices are characterized by porosimetry, $\mathrm{N}_{2}$ adsorption, and microscopy techniques in order to search for a relationship between glass hydrophobicity and the observed changes in protein structure.

\section{Materials and methods}

\subsection{Protein preparation}

Apomyoglobin was prepared by 2-butanone extraction of myoglobin from horse heart (Sigma-Aldrich, lot M-1882) with subsequent dialysis against $5.0 \mathrm{~mm}$ potassium acetate buffer, $\mathrm{pH}$ 5, containing $1.0 \mathrm{~mm}$ dithiothreitol and $0.50 \mathrm{~mm}$ ethylenediaminetetraacetic acid (EDTA from Aldrich). The dialyzed solution was filtered using a $0.22 \mu \mathrm{m}$ syringe filter (Millex, Millipore) to remove any potential aggregates prior to encapsulation. The concentration of the apomyoglobin stock was determined by CD using the following formula [34]:

$C=\frac{\Theta \times 100 \times \mathrm{MW}}{[\Theta]_{\mathrm{mol}} \times d \times N_{\mathrm{a}}}$

where $[\Theta]_{\text {mol }}$ is the molar ellipticity for apoMb $\left(-19,000 \mathrm{deg} \mathrm{cm}^{2} \mathrm{dmol}^{-1}\right.$ at $222 \mathrm{~nm}), d$ is the path length of the cuvette $(0.2 \mathrm{~cm})$, MW is the protein molecular weight $\left(16,951 \mathrm{~g} \mathrm{~mol}^{-1}\right.$ for apoMb), $\Theta$ is the measured ellipticity (degrees), $N_{\mathrm{a}}$ is the number of amino acid residues per protein $\left(N_{\mathrm{a}}=153\right.$ for apoMb), the factor 100 originates from the conversion of the molar concentration to the $\mathrm{dmol} / \mathrm{cm}^{3}$ concentration unit, and $C$ is the protein concentration $(\mathrm{mg} / \mathrm{ml})$. After prolonged storage at $5{ }^{\circ} \mathrm{C}$, the structural integrity of apomyoglobin was confirmed by reappearance of the Soret band at $408 \mathrm{~nm}$ upon heme addition (Hewlett-Packard 8452A Diode Array Spectrophotometer). Pure ribonuclease A Type XII-A from bovine pancreas was purchased from Sigma-Aldrich (R5500). RNase A (MW =13,674 $\mathrm{g} \mathrm{mol}^{-1}, N_{\mathrm{a}}=124$ ) was dissolved in potassium phosphate buffer $(10 \mathrm{~mm})$ to obtain an approximate concentration of $30 \mathrm{mg} / \mathrm{ml}$. The final concentration of the RNase A stock solution was determined from the absorption peak at $276 \mathrm{~nm}$ using $A_{276}^{1 \%}=\$ .09$ for a $1-\mathrm{cm}$ path length [35]. MilliQ-purified water was utilized for all solutions (Millipore).

\subsection{Protein encapsulation in sol-gel glasses}

Proteins were encapsulated in sol-gel glasses made from TMOS (Acros) and a series of alkyltrimethoxysilane reagents, $\mathrm{RSi}(\mathrm{OMe})_{3}$, where $\mathrm{R}=$ methyl, ethyl, $n$-butyl, or $n$-hexyl, (purity $>99 \%$ ) from Gelest, Inc. (Morrisville, PA, USA). $n$-Propyltrimethoxysilane was supplied by Aldrich. Molar ratios of 5, 10, and 15\% of the organically-modified silane relative to total silane were calculated on the basis of $6.78 \mathrm{mmol}$ of total Si content $(2.00 \mathrm{ml}$, in the case of pure TMOS). The sol was obtained by co-hydrolysis of TMOS with the alkoxysilane precursors. For a typical experiment, the necessary volume of silane precursors for a given glass was mixed in the same tube, divided into two equal aliquots, and then $214 \mu \mathrm{L}$ of water and $30 \mu \mathrm{L}$ of $0.040 \mathrm{~N} \mathrm{HCl}$ were added to each aliquot. Hydrolysis of the sol was performed by sonication in an ice-water bath for 30 min (Branson 1510 ultrasonic cleaner). After verifying by eye that a homogenous solution was achieved, the two aliquots were combined, and a $2.0 \mathrm{ml}$ volume of the sol was added to $3.0 \mathrm{ml}$ of the aqueous solution containing the desired protein in $5 \mathrm{~mm}$ potassium phosphate buffer, $\mathrm{pH}$ 7. The final concentration of protein per total volume of sol-gel mixture was $0.49 \mathrm{mg} / \mathrm{ml}$ for apoMb and $7.0 \mathrm{mg} / \mathrm{ml}$ for RNase A; the higher concentration of RNase A is required for $C D$ analysis in the near-UV region. The sol-gel solution was gently mixed and immediately transferred to a plastic cassette of 1-mm spacing to ensure a uniform thickness (Invitrogen \#NC2010). The cassette was covered with parafilm and stored upright at $5{ }^{\circ} \mathrm{C}$. Solid glasses were layered with $1 \mathrm{ml}$ of water after aging for $12-24 \mathrm{~h}$ and stored at $5{ }^{\circ} \mathrm{C}$ for 2-3 weeks before use. After the wet-aging period, the glass sheets were removed by breaking open the cassette. Rectangular pieces of glass were cut with a razor blade and immersed in $3 \mathrm{ml}$ of phosphate buffer solutions ( $\mathrm{pH} 7)$ at two different concentrations for equilibration (10 $\mathrm{mm}$ and $1.0 \mathrm{M}$ ) The glass samples were left immersed overnight at room temperature prior to $C D$ analysis. No leaching of the protein from the glasses was observed at ambient temperatures.

\subsection{Circular dichroism spectroscopy}

Changes in protein structure were monitored by CD spectra as recorded on an Aviv Model 215 circular dichroism spectrometer equipped with a Peltier-type thermoelectric cell holder. Glass samples were placed in a $2 \mathrm{~mm}$ path quartz cuvette filled with the corresponding equilibration buffer during $C D$ analysis. Spectra were recorded at $25{ }^{\circ} \mathrm{C}$ in the far-UV region for apoMb and in the near-UV region for RNase A to monitor the secondary and tertiary structure of each protein, respectively Potassium phosphate buffer was used as the sample blank, and the background signal was subtracted from all spectra before conversion to units of molar ellipticity. The thermal stability curves were recorded in five-degree steps from 25 to $90^{\circ} \mathrm{C}$ with a 30-s delay at each temperature before recording the ellipticity at $222 \mathrm{~nm}$. Longer delays for temperature equilibration had no significant effect on the thermal denaturation profiles. The largest source of uncertainty in all CD measurements is the protein concentration $( \pm 5 \%)$. For a given figure, the same volume of stock solution of protein was used for every glass sample such that a small uniform error in calculation of protein concentration and molar ellipticity will have no effect on the interpretation of results.

\subsection{Aerogel preparation}

Prior to the physical characterizations described in Sections 2.5 and 2.6, the gels were dried at ambient temperature in a manner that minimizes shrinkage due to collapse of the pores [36,37]. Multi-step solvent exchange was undertaken with non-polar solvents to avoid the capillary action associated with drying and shrinkage $[38,39]$. First the gels were washed with acetone for 3 days in a capped vial, exchanging the acetone once per day. Subsequently, the process was repeated with $n$-pentane, a solvent of low surface tension. Next, the vials were opened and covered with aluminum foil through which a $1 \mathrm{~mm}$ diameter pinhole was made to allow slow evaporation of the pentane. The resulting solid materials were dried for $24 \mathrm{~h}$ at $37^{\circ} \mathrm{C}$ to form aerogel samples suitable for physical analysis.

\subsection{Porosity and Brunauer-Emmett-Teller (BET) surface area measurements}

The surface area and porosity determinations of aerogel samples were carried out using a Gemini apparatus from Micromeritics. The samples (ca. $40 \mathrm{mg}$ ) were cleaned by flowing nitrogen (ca. $30 \mathrm{ml} / \mathrm{min}$ ) for $6 \mathrm{~h}$ at $50{ }^{\circ} \mathrm{C}$ and for $12 \mathrm{~h}$ at $120^{\circ} \mathrm{C}$ in a Flow-Prep 060 oven, also from Micromeritics. The gases, helium for calibration (99.9990\%) and nitrogen for adsorption-desorption (99.9990\%), were obtained from L'Air Liquide (Spain). Full adsorption-desorption isotherms were recorded, and the 
multipoint BET method was used for analysis. Specific surface area was determined from the adsorption branch, whereas pore size distribution was determined from the desorption branch using the Wheeler method.

\subsection{Scanning electron microscopy (SEM) and atomic force microscopy (AFM)}

The surface morphology and microstructure of the modified and unmodified silica-based aerogels were characterized by SEM using a Hitachi S-4300 Scanning Electron Microscope. Samples were attached to aluminum stubs with double-coated carbon conductive tabs and were gold sputtered (4.5-5.2 nm) using Auto Sputte Coater by Pelco (Model SC-7). The edges of the coated samples were brushed with colloidal graphite for improved conductivity of the sample surface, dried overnight, and analyzed. The images were acquired at $5 \mathrm{kV}$. AFM measurements were performed using a Veeco Dimension 5000 instrument. AFM tips from Veeco, model TESPA, made of antimony ( $\mathrm{n}$ ) doped $\mathrm{Si}$ of radius of $8-12 \mathrm{~nm}$ were used. The vibrating frequency was in the range of $320 \mathrm{kHz}$, and the tapping mode was employed at a scanning rate of $1 \mathrm{~Hz}$. Average domain sizes (i.e. agglomerated $\mathrm{SiO}_{2}$ particles) were determined from the SEM images according to the given scale.

\section{Results}

\subsection{Protein structure in alkyl-modified silica glasses}

The average structures of proteins encapsulated in the pores of wet-aged-based silica glasses were determined by CD spectroscopy in TMOS-based glasses $\left[\mathrm{Si}(\mathrm{OMe})_{4}\right]$ that were modified by addition of alkyltrimethoxysilane precursors [RSi(OMe $\left.)_{3}\right]$. The $\mathrm{CD}$ signals originating from the protein in glass samples may be compared directly to the protein signal obtained in dilute solution because the data are normalized to units of molar ellipticity. At a fixed value of $5 \% \mathrm{RSi}(\mathrm{OMe})_{3}$ for each glass, a significant increase in the secondary structure of apomyoglobin is observed in the following order: unmodified $<$ methyl $<$ ethyl $<n$-propyl $<n$ butyl $<n$-hexyl (Fig. 1). The molar ellipticity of apoMb in the far-UV approaches the spectrum of the native protein in dilute solution as the alkyl chain length increases. At a wavelength of $222 \mathrm{~nm}$, where molar ellipticity is an approximate measure of helical content, the value for apoMb in solution is $19,000 \mathrm{deg} \mathrm{cm}^{2} \mathrm{dmol}^{1}$, whereas the molar ellipticity for the $5 \%$ hexyl-modified glass is $19,750 \mathrm{deg} \mathrm{\textrm {cm } ^ { 2 } \mathrm { dmol }}{ }^{1}$, indicating slightly more helical structure in the glass than observed in solution. By contrast, the $100 \%$ TMOS-derived glass yields the

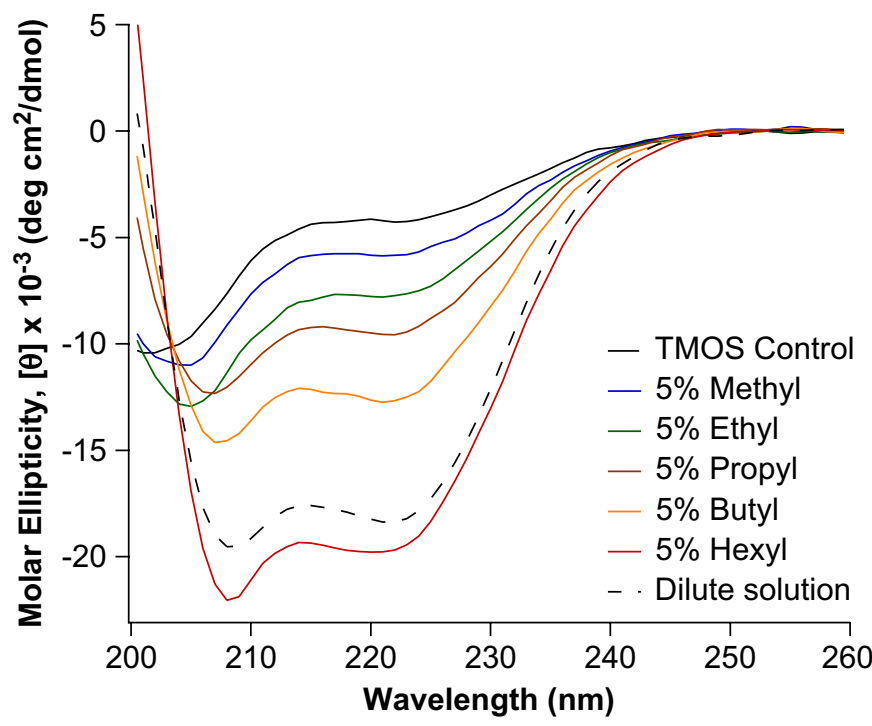

Fig. 1. The helicity of encapsulated apoMb increases with increasing chain length of the organic modifier. CD spectra in the far-UV region for apoMb in unmodified and modified glasses (solid curves) and in dilute solution (dashed curve). All spectra were measured in the presence of potassium phosphate $(10 \mathrm{~mm}, \mathrm{pH} 7)$. weakest $\mathrm{CD}$ signal indicating that apoMb is largely unfolded in the control matrix, as reported previously (Fig. 1) [22-24].

The relationship between protein structure and glass hydrophobicity is confirmed and strengthened by monitoring apoMb structure in a set of glasses of increasing molar content for each of the alkylsilane reagents employed in this study. When the molar content of $\mathrm{RSi}(\mathrm{OMe})_{3}$ is varied from 0 to $15 \%$, a corresponding increase in helicity of apoMb is observed for each set of glasses (Fig. 2). The hexyl-modified glass could not be analyzed above a value of $5 \%$ incorporation due to a loss of optical transparency; the other four glasses were observed to lose transparency above $15 \%$. We also attempted to make a glass with $n$-octyltrimethoxysilane, but this reagent led to a phase separation such that formation of a homogenous transparent glass was not possible, even at a low molar content of $5 \%$.

The near-UV CD spectra of another protein, RNase A, were obtained following encapsulation in the same glasses as apoMb (Fig. 3). The near-UV spectra arise from asymmetry in the packing around aromatic residues and, thus, report on changes in the tertiary structure of RNase A. The changes in molar ellipticity indicate that RNase A structure also is enhanced as the hydrophobicity of the glass increases (Fig. 3). Unfortunately, changes in the tertiary structure of apoMb cannot be monitored by this technique because the signal originating from its two tryptophan residues offset each other, resulting in a featureless spectrum [40].

In previous studies, molar salt solutions were shown to have a significant effect on the structure of apoMb in unmodified glasses [23]. As shown in Fig. 4, an increase in phosphate concentration from $10 \mathrm{~mm}$ to $1.0 \mathrm{~m}$ yields an increase in the molar ellipticity of apoMb in the unmodified glass from 4300 to $15,000 \mathrm{deg} \mathrm{cm}^{2} \mathrm{dmol}^{1}$ at $222 \mathrm{~nm}$, as expected. When the alkyl-modified glasses were equilibrated in the $1 \mathrm{~m}$ potassium phosphate solution, the salt effect on apoMb structure was more subtle and diminished with increasing chain length of the alkyl group. In the $10 \%$ ethyl-modified glass, for example, phosphate addition did not induce the same helical endpoint as the control glass made from 100\% TMOS (Fig. 4). Thus, the favourable effects of molar phosphate concentration and glass hydrophobicity on protein structure are not additive. This result strongly suggests that the effects of altered glass hydrophobicity and molar salt addition are mediated by different mechanisms. Not surprisingly, the addition of $1 \mathrm{~m}$ phosphate had no effect on the

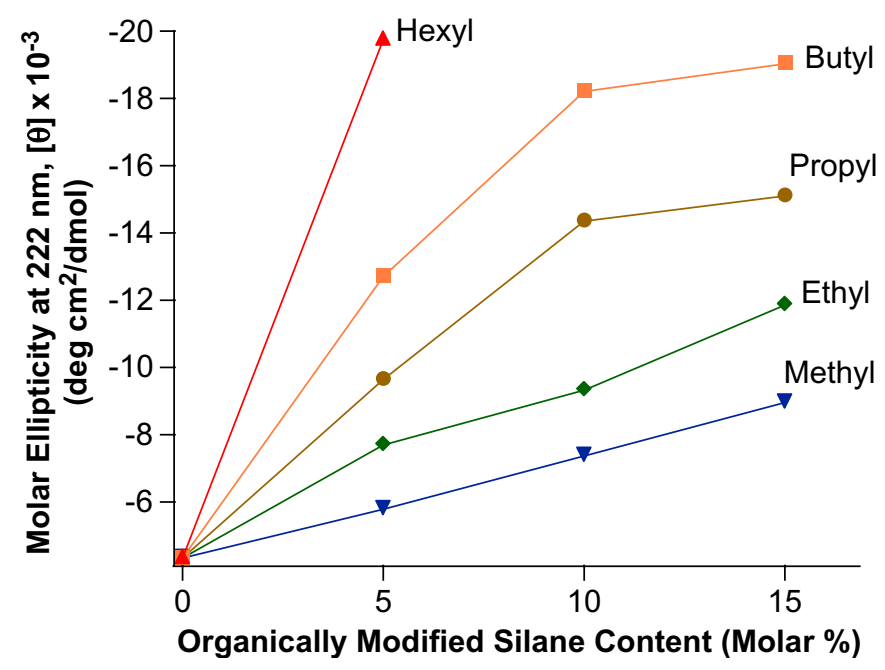

Fig. 2. ApoMb structure as a function of molar content and chain length of the alkylsilane precursor. The molar ellipticity at $222 \mathrm{~nm}$ is proportional to the helical content of the protein, and the ellipticity value for the native protein in dilute solution is $19 \times 10^{3} \mathrm{deg} \mathrm{cm}^{2} \mathrm{dmol}^{1}$. 


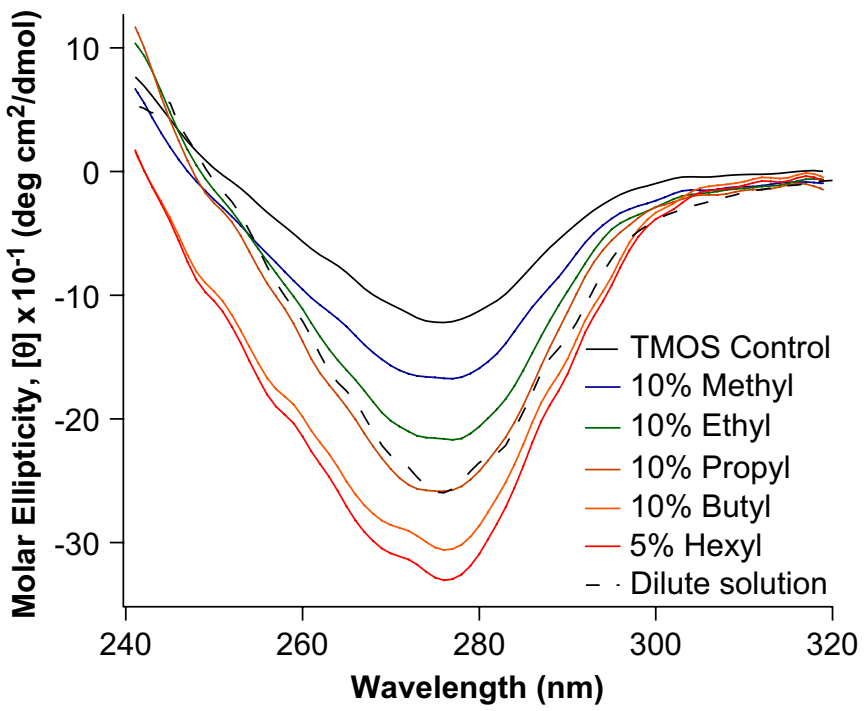

Fig. 3. CD spectra in the near-UV region for RNase A encapsulated in unmodified and modified glasses (solid curves) and in dilute solution (dashed curve).

native-like structure of apoMb in the $10 \%$ butyl-modified glass (Fig. 4).

\subsection{Thermal stability of the proteins in the glasses}

One major goal of glass encapsulation is to enhance protein stability. The data in Fig. 5 indicate that apoMb is extremely stable against thermal denaturation in both the modified and unmodified glasses when heated from 25 to $90^{\circ} \mathrm{C}$. For example, the molar ellipticity of apoMb in the $10 \%$ butyl-modified glass only decreases

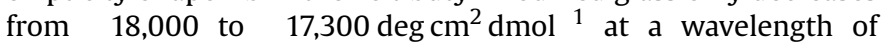
$222 \mathrm{~nm}$. At the other extreme, apoMb in solution proceeds to unfold through a broad transition from 19,000 to $8500 \mathrm{deg} \mathrm{cm}^{2} \mathrm{dmol}^{1}$ (Fig. 5(a)). When a glass sample is held at $90{ }^{\circ} \mathrm{C}$ for extended times (30 and $60 \mathrm{~min}$ ), apoMb structure remains stable. The CD spectra of the $10 \%$ butyl-modified glass show the features of a folded protein even after a long period of heat treatment; the CD signal at $222 \mathrm{~nm}$

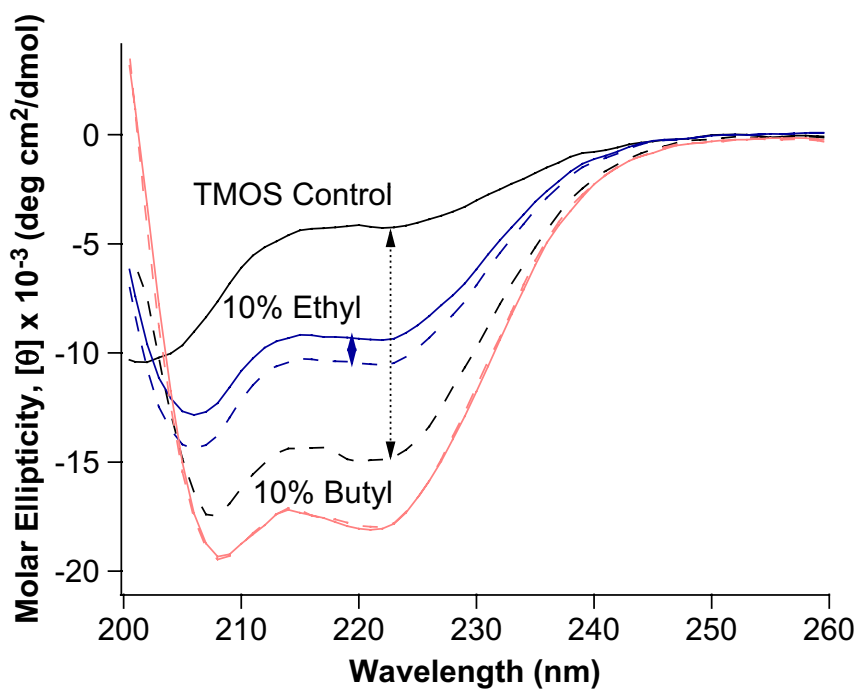

Fig. 4. Influence of potassium phosphate concentration on apoMb structure in three different glasses: an unmodified TMOS glass, a $10 \%$ ethyl-modified glass, and a $10 \%$ butyl-modified glass. Each glass sample was equilibrated in $10 \mathrm{~mm}$ phosphate (solid curve) and in $1.0 \mathrm{~m}$ phosphate (dashed curve).
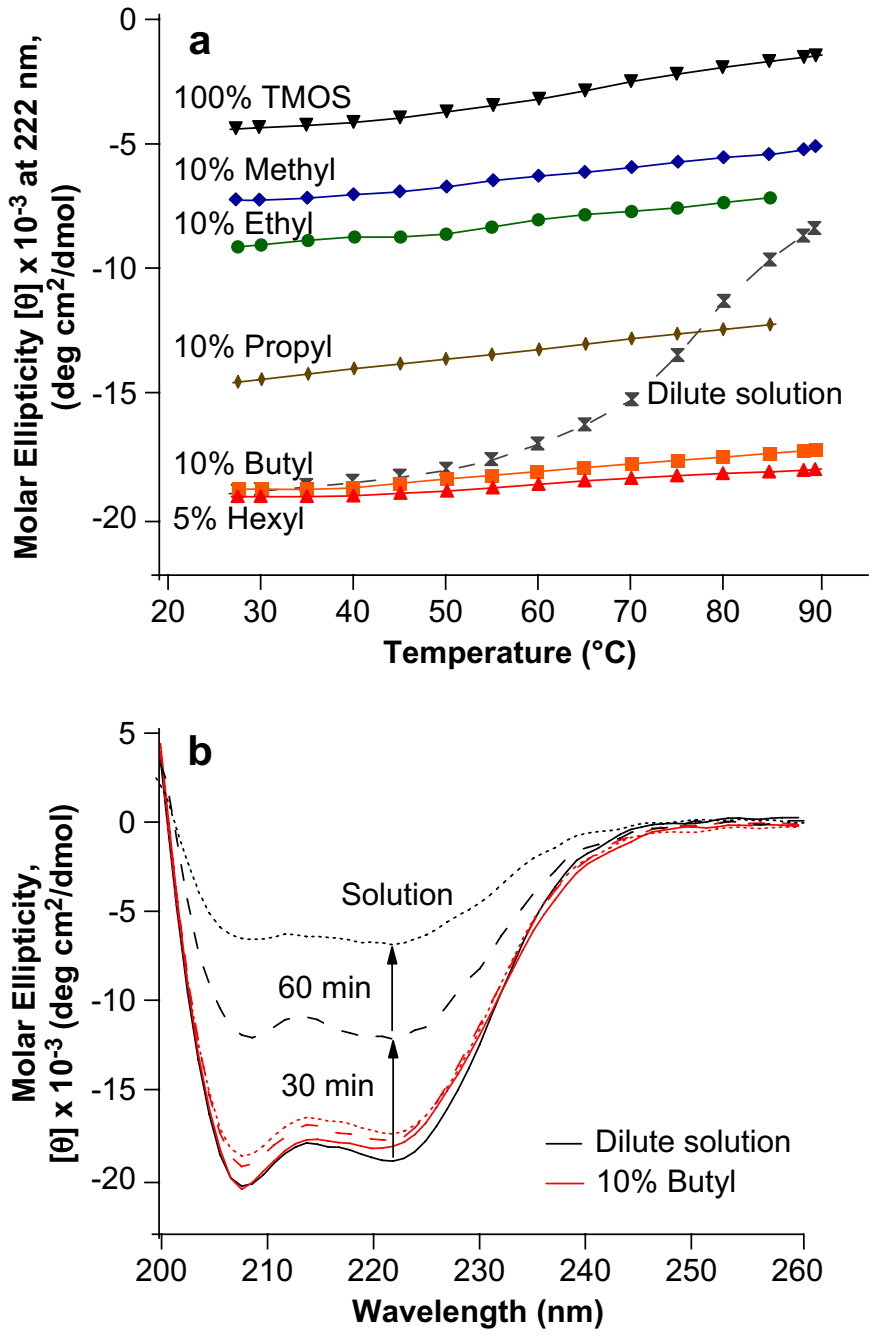

Fig. 5. Remarkable thermal stability of apoMb in unmodified and organically-modified glasses relative to dilute solution. (a) Temperature profiles. All samples were analyzed at $222 \mathrm{~nm}$ in potassium phosphate solution (10 mm, pH 7). (b) Changes in apoMb structure after continuous heat treatment at $90^{\circ} \mathrm{C}$ for $30 \mathrm{~min}$ (dashed curve) and $60 \mathrm{~min}$ (dotted curve), as indicated on the graph.

decreases only slightly from 18,000 to $17,100 \mathrm{deg} \mathrm{cm}^{2} \mathrm{dmol}{ }^{1}$ after holding the sample at $90^{\circ} \mathrm{C}$ for $60 \mathrm{~min}$ (Fig. 5(b)). This modest change in signal may originate from a minor leaching problem at the elevated temperature. In contrast, the ellipticity of the protein in dilute solution decreases drastically after extended times at $90{ }^{\circ} \mathrm{C}$ due to aggregation and precipitation of the unfolded protein (Fig. 5(b)).

\subsection{Specific surface area and porosity of the silica-based aerogels}

The $C D$ results suggest that the alkyl chain of the organicallymodified glasses may induce a length-dependent change in one or more physical properties of the host matrix, contributing to an apparent increase in the fraction of properly-folded protein. To address this possibility, the specific surface areas and porosities of both the modified and unmodified glasses were determined after conversion to aerogels. The results for TMOS and for the modified host matrices of $10 \%$ molar composition ( $\mathrm{R}=$ methyl, ethyl, propyl, butyl) or $5 \%$ composition ( $\mathrm{R}=$ hexyl) are summarized in Table 1 . The measurements indicate that pore volume and pore size generally decrease upon alkyl modification of the silica surface, both in the presence and absence of protein. The average pore size decreases 
Table 1

Physical properties of unmodified and alkyl-modified glasses, with and without apomyoglobin encapsulation

\begin{tabular}{|c|c|c|c|c|c|c|}
\hline \multirow[t]{2}{*}{ Glass composition } & \multicolumn{3}{|l|}{ Without protein } & \multicolumn{3}{|c|}{ With protein encapsulation } \\
\hline & $\begin{array}{l}\text { Specific surface area, } \\
\text { SBET }\left(\mathrm{m}^{2} / \mathrm{g}\right)\end{array}$ & $\begin{array}{l}\text { Pore volume, } \\
\text { Vp }\left(\mathrm{cm}^{3} / \mathrm{g}\right)\end{array}$ & $\begin{array}{l}\text { Average pore } \\
\text { diameter (nm) }\end{array}$ & $\begin{array}{l}\text { Specific surface area, } \\
\text { SBET }\left(\mathrm{m}^{2} / \mathrm{g}\right)\end{array}$ & $\begin{array}{l}\text { Pore volume, } \\
\text { Vp }\left(\mathrm{cm}^{3} / \mathrm{g}\right)\end{array}$ & $\begin{array}{l}\text { Average pore } \\
\text { diameter }(\mathrm{nm})\end{array}$ \\
\hline $100 \%$ TMOS & 635 & 1.885 & 10.8 & 579 & 1.709 & 8.9 \\
\hline 10\% Methyl & 969 & 0.983 & 4.8 & 1006 & 0.937 & 4.5 \\
\hline 10\% Ethyl & 811 & 0.738 & 4.2 & 779 & 0.677 & 4.0 \\
\hline 10\% Propyl & 925 & 0.867 & 4.2 & 819 & 0.663 & 4.0 \\
\hline $10 \%$ Butyl & 904 & 0.828 & 4.2 & 1011 & 0.912 & 4.0 \\
\hline $5 \%$ Hexyl & 919 & 0.850 & 4.0 & 952 & 0.898 & 3.8 \\
\hline
\end{tabular}

from $10.8 \mathrm{~nm}$ to about $4 \mathrm{~nm}$ in the absence of apoMb, and the average pore size decreases from $8.9 \mathrm{~nm}$ to about $4 \mathrm{~nm}$ when apoMb is present. Thus, all of the modified glasses, from methyl to hexyl, exhibit the same approximate pore size $(\sim 4 \mathrm{~nm})$ with or without protein encapsulation. The reduced pore sizes are accompanied by a $25-75 \%$ increase in the specific surface area of the modified silica matrices relative to the unmodified glass (Table 1 ).

In Fig. 6, two physisorption isotherms are shown that are typical of those obtained for the modified and unmodified silica glasses. The isotherms were found to be independent of protein addition; glasses of the same composition yield the same profile, with and without apoMb encapsulation. Although both isotherms have the characteristics of a mesoporous silica material, it can be seen that the unmodified glass yields a different type of isotherm compared to the organically-modified host matrix (Fig. 6). The hysteresis profile for the $100 \%$ TMOS-derived glass, with or without protein encapsulation, corresponds to type B in de Boer's classification, now referred to as type $\mathrm{H} 3$ by IUPAC $[41,42]$. This classification is associated with adsorption into slit-shaped pores or into the space between parallel platelets. In contrast, all of the modified silica samples exhibit type E hysteresis in de Boer's classification (type $\mathrm{H} 2$ by IUPAC). This profile is associated with adsorption into bottleneck-shaped pores, that is, pores for which the inner compartment is wider than the entrance.

\subsection{Surface morphology of glasses}

The microstructures of the unmodified TMOS-derived and the modified alkylsiloxane-derived aerogels were characterized by

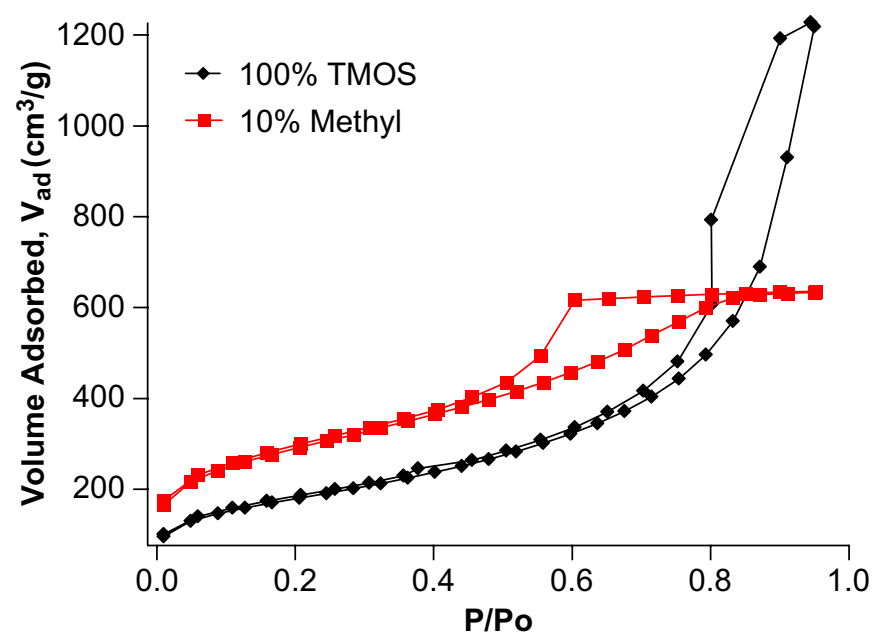

Fig. 6. $\mathrm{N}_{2}$ adsorption-desorption isotherms for the unmodified and $10 \%$ methylmodified glasses. All of the alkyl-modified glasses in this study yield an isotherm similar to that shown for the $10 \%$ methyl glass, and addition of protein has no significant effect on the hysteresis profiles. scanning electron microscopy, with and without apoMb addition. Interestingly, the presence of apoMb has a major influence on the surface morphology of the host glass materials. The surface of glasses formed in the absence of protein appears highly homogeneous with an even distribution of silica particles (Fig. 7(a,c)), whereas all glasses containing apoMb exhibit serpentine-like features, as exemplified by the images of the 100\% TMOS and $10 \%$ ethyl-modified glasses (Fig. 7(b,d)). Moreover, in the case of the unmodified silica aerogel, the serpentine domains appear to form semi-regular arrays (Fig. 7(b)). Digital analysis of each image indicates a correlation between alkyl chain length and the average domain size of the serpentine substructures (Fig. 8). When a $10 \%$ ethyl-modified glass was examined by atomic force microscopy in tapping mode, the higher depth contrast of the $10 \times 10 \mu \mathrm{m}$ square image reveals a distribution of spiral chains of $\sim 20 \mathrm{~nm}$ size formed by the interconnected silica particles (Fig. 9).

\section{Discussion}

Hydrophobic, organically-modified silica glasses have been used previously to enhance the activity of glass-encapsulated lipases [718]. The hydrophobic character of such glasses has been verified by several means including contact angle measurements [43], solidstate ${ }^{29} \mathrm{Si}$ MAS NMR, and Fourier transform infrared spectroscopy $[17,44]$. Although most enzymes prefer an aqueous environment, it is rational to place lipases in a hydrophobic environment because these enzymes mediate reactions at lipid-water interfaces and because the substrates of these enzymes are highly non-polar molecules. However, studies involving glass-encapsulated lipases typically compare rates of product formation without providing any insight on whether or not the glass composition also influences enzyme structure. If a change in glass hydrophobicity alters both the fraction of properly-folded enzyme and the partitioning of the enzyme substrate into the matrix, then it would be difficult to discern one effect from the other based solely on kinetic measurements of enzyme activity.

In the current work, we examine the structure of glass-encapsulated apoMb, a model protein that is not expected to favour a hydrophobic environment. We demonstrate that relatively small amounts of alkyl-modifying precursors (5-15\%) can have a drastic effect on the helical content of the glass-entrapped protein. We were unable to examine all of the hydrophobic glasses above $15 \%$ modification due to a phase separation phenomenon that leads to a loss of optical transparency. Phase separation can be minimized by co-hydrolysis of the organosilane reagents, as employed here, instead of separate hydrolyses followed by mixing $[8,45,46]$. Our glasses appear to be under the reported threshold for phase separation of co-hydrolyzed samples; for example, glasses with up to $20 \%$ by volume of methyltriethoxysilane or $5 \%$ propyltrimethoxysilane have been prepared in tetraethoxysilane (TEOS) with no sign of phase separation, as monitored by several optical techniques $[8,46]$. The higher threshold for propyltrimethoxysilane in the current 

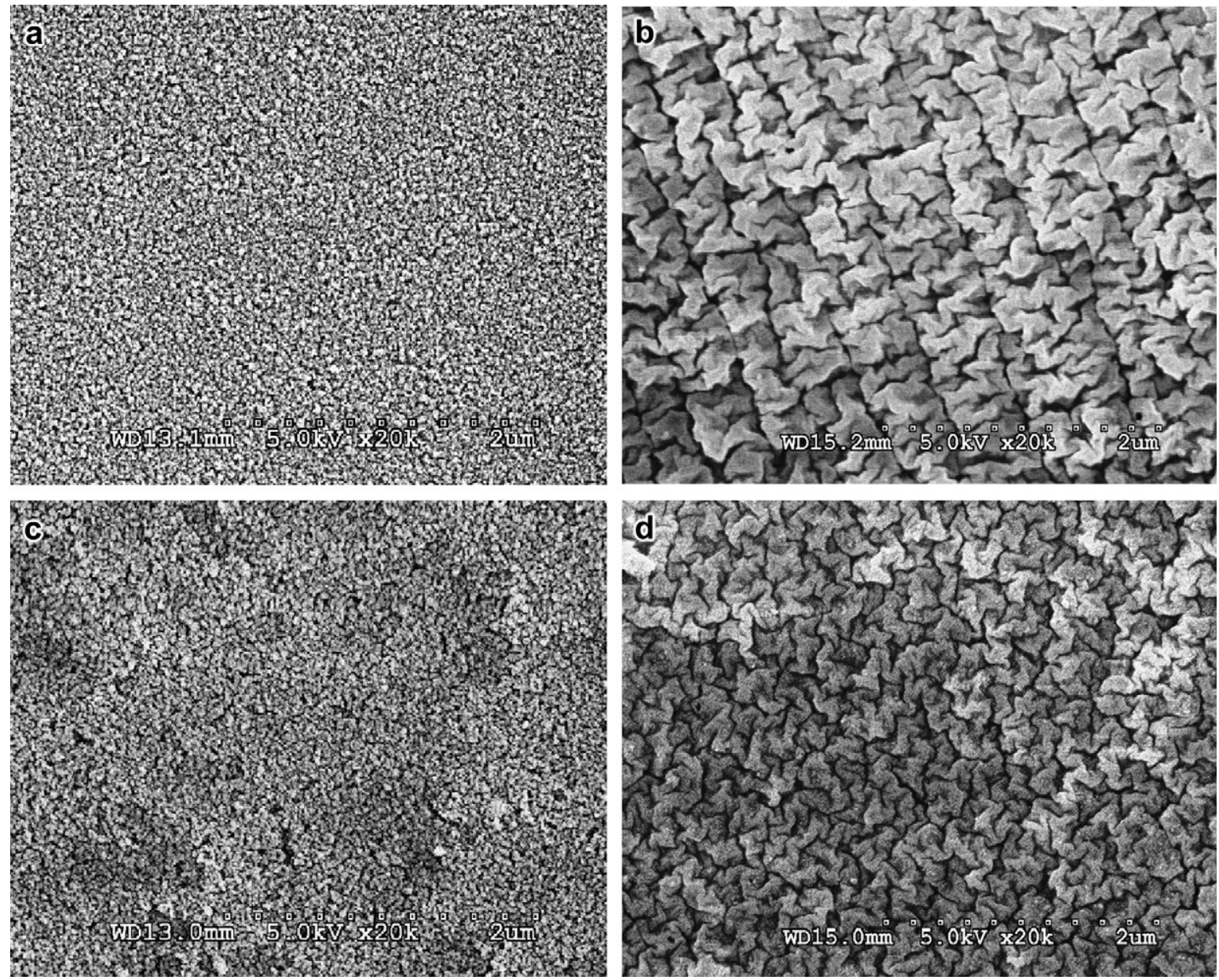

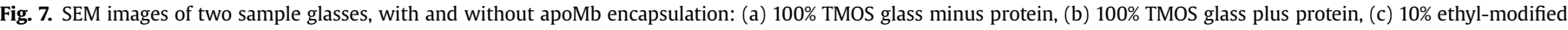
glass minus protein, (d) 10\% ethyl-modified glass plus protein.

work ( $15 \%$ molar) may be due to slight differences in preparation (TMOS versus TEOS) and in the commercial source of reagents.

The helical content of apoMb, measured as molar ellipticity in the far-UV region, was found to increase as the alkyl chain length of the precursor increased from one to six carbons (Fig. 1) or as the content of the hydrophobic precursor increased (Fig. 2). Importantly, the secondary structure of encapsulated apoMb did not

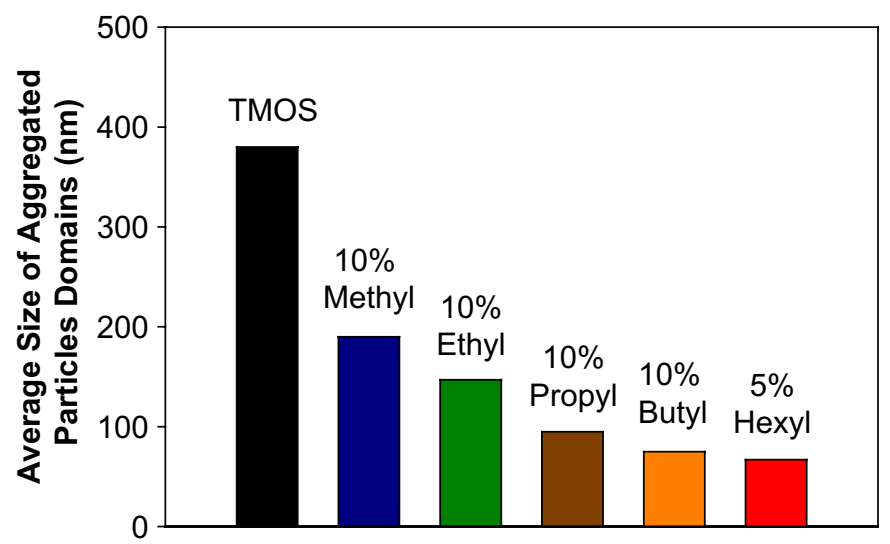

Fig. 8. Domain size of serpentine structures as a function of alkyl chain length for glasses made with the same concentration of apoMb. Domain size was estimated from the corresponding SEM image. exceed that of the native protein in dilute solution for all but one of the glasses examined in this study; the 5\% hexyl-modified glass resulted in a slightly more helical protein than observed in solution. If the $\mathrm{CD}$ spectrum of the glass-encapsulated protein had become significantly more negative in the far-UV region than the solution structure (e.g. below $24,000 \mathrm{deg} \mathrm{cm}^{2} \mathrm{dmol}^{1}$ at $222 \mathrm{~nm}$ ), it might indicate that the globular, tertiary structure of the protein has been compromised. We know of only one condition where a protein may gain helical content without a simultaneous gain in tertiary structure, and that is the case where water-miscible alcohols are added to the solvent phase. Because we never add alcohol to any of the samples in this work, and because apoMb is a protein with $\sim 60 \%$ $\alpha$-helical structure in the native state, it seems likely that the gain in helical content of this protein in hydrophobic, organicallymodified glasses is accompanied by a gain in proper tertiary structure. Our suggestion that apoMb acquires more tertiary structure in alkyl-modified glasses is reinforced by the fact that the tertiary structure of another protein, RNase A, was not diminished and was somewhat enhanced following encapsulation in the same glasses, as monitored by near-UV CD (Fig. 3). A hyperhelical structure relative to dilute solution has been reported for apoMb following encapsulation in trifluoropropyl-modified glasses [24]. This result was attributed to the presence of organic fluorine, and, because the helicity of the protein never exceeded that of the heme-bound holoprotein, the observed hyperhelical structure may represent the true native state that prevails in a crowded environment [21]. 


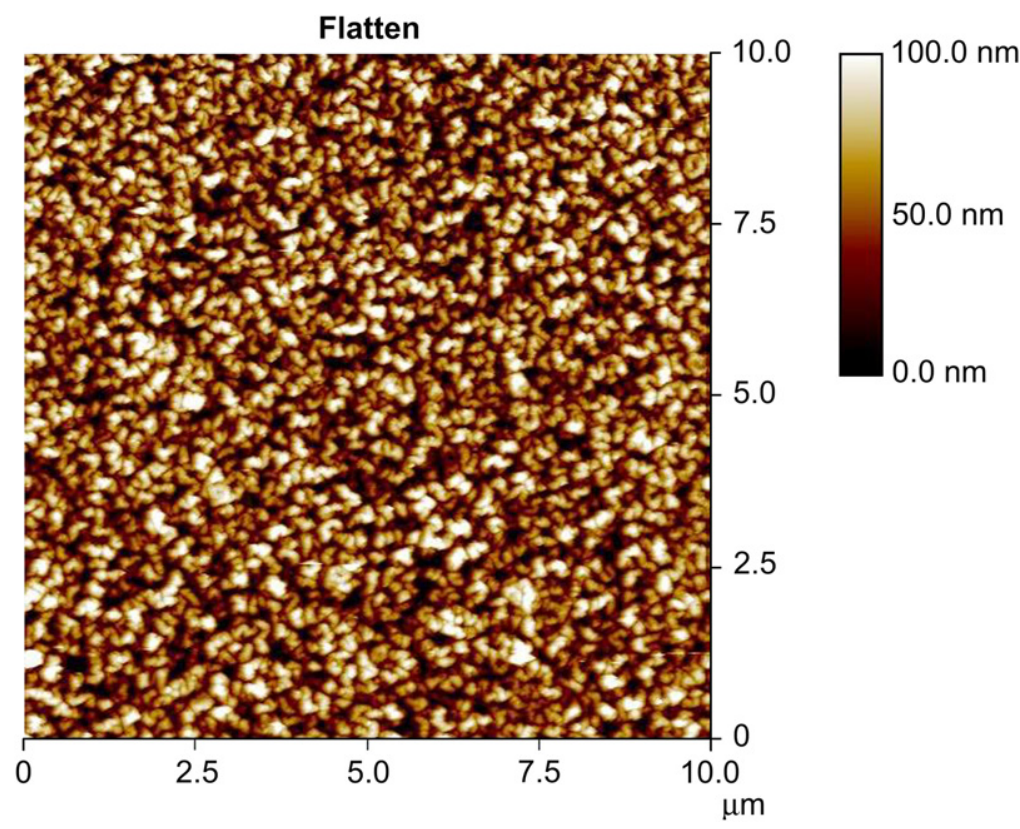

Fig. 9. AFM image of a $10 \%$ ethyl-modified glass with encapsulated apoMb. Spiral chains of interconnected silica particles are evident.

To better understand the relationship between glass hydrophobicity and protein structure, we characterized some of the physical properties of alkyl-modified glasses using the tools of materials science. BET measurements indicate that all five alkyl precursors have a comparable effect on the glass, independent of chain length; surface area is increased and pore volume is decreased to a similar extent for all modified glasses relative to the unmodified glass (Table 1). This result is consistent with the formation of smaller silica particles prior to gelation due to a preponderance of reactionterminating alkylsilane groups on the surface of the growing particle; at much higher concentrations of the alkyltrimethoxysilane precursor, phase separation can lead to the formation of crystalline oligomers, resinous materials, and precipitates [47].

Comparing columns three and six of Table 1 , one observes a small but consistent decrease in average pore size of all glasses upon addition of protein. The effect of protein addition on pore size suggests a direct interaction between the silica particles and protein molecule during sol-gel processing. However, there is clearly no correlation between pore size and apoMb structure since $10 \%$ ethyl-, propyl-, and butyl-modified glasses yield the same pore size (Table 1 ), whereas the structure of the protein differs greatly in the same three glasses (Fig. 2).

The influence of pore size on the biological activity of enzymes in sol-gel matrices has been a subject of discussion by other investigators. Reetz and co-workers noted that lipase activity in alkylmodified silica host materials might be expected to increase with increasing pore volume due to better accessibility of the substrate, but the opposite was found experimentally [7]. The authors concluded that the catalytic activity of lipases is not related to pore size but most likely a function of other factors related to the glass hydrophobicity, such as partitioning of the reactants or an interface-dependent conformational change in a specific loop that activates the enzyme. In a recent paper, Noureddini and Gao came to the same conclusion after finding no correlation between lipase activity and the degree of crosslinking or the specific surface areas of their alkyl-modified glasses [18]. Our data provide direct evidence for the conformational change hypothesis; even though nature did not design apoMb to function at a hydrophobic interface, apoMb structure was greatly enhanced in alkyl-modified glasses. We propose that the fraction of properly-folded lipase also may be increased by encapsulation in hydrophobic glasses and that the increase in functional lipase is primarily responsible for the higher activity detected in modified glasses relative to unmodified glasses.

It should be noted that hydrophilic organosilane precursors also have been employed to alter the surface chemistry of sol-gel glasses and to enhance the activity of encapsulated enzymes. Some of the common hydrophilic substitutions include glasses modified with aminopropyl [48-51], carboxyethyl [48,49], glycidoxypropyl [50,51], and diglyceryl or gluconamidyl groups [52-54]. Of special interest with regard to hydrophilic organically-modified glasses, Ackerman and co-workers have reported outstanding enzyme activities following protein adsorption into functionalized mesoporous silica prepared using a non-ionic block copolymer surfactant as the template $[48,49]$. For example, the specific activity of organophosphorus hydrolase was found to increase by more than two-fold relative to dilute solution when entrapped in a functionalized glass modified with a $2 \%$ coverage of carboxyethyl groups on the internal silanol wall [48]. Although the superactivity of this enzyme relative to solution measurements is promising [55], the mechanism responsible for the enhanced biocatalysis is not fully understood. Three possibilities include (a) a glass-induced enhancement in native structure following partial unfolding or aggregation of the enzyme during the reported freeze-thaw step, leading to a deceptively low activity in solution, (b) a favourable partitioning of the enzyme substrate into the silica environment such that the activities of the free and immobilized enzymes are not compared at the same effective substrate concentrations, and (c) crowding and confinement effects on the enzyme reaction due to the glass environment, allowing one to measure the true kinetics that would prevail in a living cell $[19,20]$.

If one assumes that the average pore size of the bulk glass also reflects the average size of a protein-occupied pore, then one must conclude that glass-encapsulated apoMb inhabits an extremely confined environment; the calculated pore size is approximately $4 \mathrm{~nm}$ in all alkyl-modified glasses, and the largest dimension of the protein is $4.2 \mathrm{~nm}$ from the crystal structure $[56,57]$. It should be noted that the actual pore size of a wet-aged glass before drying may be much larger than $4 \mathrm{~nm}$. Harreld coworkers [58] reported that the pore size obtained by drying with 
supercritical $\mathrm{CO}_{2}$ is approximately $11 \mathrm{~nm}$ for a $10 \%$ methylmodified glass, whereas the same glass resulted in an average pore diameter of $3.8 \mathrm{~nm}$ when dried from pentane, the same method employed in the current work. Thus, a molecule of apoMb should have ample room to rotate and alter conformation within the pores of a wet-aged glass, but the environment is a crowded one which presumably leads to the striking thermal stability of the protein (Fig. 5).

The mobilities of glass-entrapped proteins have been characterized by fluorescence anisotropy [26,59-62], tryptophan phosphorescence [63], and photobleaching experiments [62]. In addition to apoMb, enhanced conformational stability at elevated temperatures has been observed for many glass-entrapped proteins including $\alpha$-lactalbumin [22], lysozyme [22,24], human serum albumin [24,26,54], creatine kinase [31], monellin [59], oncomodulin [64], cytochrome $c$ [65], and carbonic anhydrase [66]. The outstanding thermal stability of proteins in organically-modified glasses, as demonstrated here for apoMb, bodes well for the use of such biomaterials in industry, including the development of new nanobiodevices $[6,27]$.

The $\mathrm{N}_{2}$ adsorption/desorption isotherm curves indicate a change in pore shape upon addition of an alkyl-modifying precursor, whether or not apoMb is present (Fig. 6). In the unmodified glass (100\% TMOS), slit-shaped pores are prevalent, whereas bottleneck-shaped pores are observed for all of the alkyl-modified glasses. Unfortunately, the difference in pore shape fails to explain the observed changes in protein structure because the same shape (hysteresis classification) was observed for all aerogels made from alkyl-modified glasses, independent of chain length. These experiments were necessary, however, to narrow our search for the critical parameter that links protein structure (and biological activity) to the changes in glass hydrophobicity.

The only parameter reported here that correlates with the observed changes in protein structure is the change in surface morphology of the glass, as monitored by SEM (Fig. 7). The spiralshaped domains were only observed in the presence of apoMb, and the domain size decreased with increasing hydrophobicity (Fig. 8). This result suggests that apoMb may serve as a template or seed for agglomeration of the silica particles during the gelation process, leading to the unusual morphology. In the case of the unmodified glass, protein encapsulation resulted in the largest domain structures and appeared to form a semi-array pattern. The smaller domain size of the alkyl-modified glasses may reflect a change in the strength of the putative silica-protein interactions that lead to the serpentine microstructure. The presence of similar spiral-shaped particle domains has been observed in hydrophobic aerogel beads made from sodium silicate (water-glass) using trimethylchlorosilane and hexamethyldisilazane as surfacemodifying agents [67]. The authors suggested that the observed microstructure was due to their preparation method which involved the dropwise addition of the silica sol into a stirred beaker of $n$-hexane. In another study, the surface morphology of a poly(vinyl alcohol)-modified glass changed significantly upon encapsulation of the protein urease [68]. The surface mean roughness increased from $0.21 \mathrm{~nm}$ in the absence of protein to $2.64 \mathrm{~nm}$ in the presence of protein, as measured by AFM. This observation is consistent with the abrupt change in surface morphology reported here upon addition of apoMb (Fig. 7).

To a biochemist, the enhanced structure of apoMb with increasing hydrophobicity of the glass is a dilemma; one would expect a hydrophobic environment to favour the unfolded conformation of a protein because, once unfolded, the hydrophobic core of the folded state should prefer to interact with its hydrophobic surroundings. The results presented in this paper suggest that silicaprotein interactions do indeed occur, leading to morphological changes in the host matrix surface, but the mechanism by which glass hydrophobicity enhances the helical content of apoMb remains unresolved.

\section{Conclusions}

Glass hydrophobicity can have a major influence on the structure of a protein encapsulated in silica matrices. By using a series of modifying reagents that incorporate alkyl groups of increasing chain length, we were able to discern the influence of hydrophobicity on the properties of the glass and on the structure of the protein in a rational manner. The observed changes in protein structure were not linked to any specific physical property of the glass matrix, although we report an intriguing correlation between alkyl chain length and surface morphology. Our results suggest that silica-derived biomaterials can be engineered or optimized for specific applications by selecting the appropriate surface chemistry and that biocompatibility may depend on the proper balance of hydrophilic and hydrophobic groups; in our case, the most hydrophilic surface (unmodified silica) was the least compatible with protein structure. Previous studies were unable to pinpoint why lipase activity is increased in organically-modified glasses, but our work strongly suggests that the enhancement in enzyme activity is due, at least in part, to an increase in the fraction of properly-folded functional enzyme. The favourable effect of hydrophobic glasses on protein conformation may be realized by other encapsulated proteins since our model protein, apoMb, was not expected to benefit from such an environment. Further work is needed to determine the generality of encapsulation effects on the structure and function of proteins in modified glasses of low hydrophobic content.

\section{Acknowledgements}

This project is funded by a grant to DKE from the National Institutes of Health, MBRS-SCORE Program (grant \#S06 GM008192). SEM and AFM images were taken by ML at Symyx Technologies (Santa Clara, CA).

\section{References}

[1] Gill I, Ballesteros A. Bioencapsulation within synthetic polymers (Part 1): sol-gel encapsulated biologicals. Trends Biotechnol 2000;18:282-96.

[2] Jin W, Brennan JD. Properties and applications of proteins encapsulated within sol-gel derived materials. Anal Chim Acta 2002;461:1-36.

[3] Bettati S, Pioselli B, Campanini B, Viappiani C, Mozzarelli A. Protein-doped nanoporous silica gels. In: Encyclopedia of nanoscience nanotechnology, vol. 9; 2004. p. 81-103.

[4] Pierre AC. The sol-gel encapsulation of enzymes. Biocatal Biotransform 2004 22:145-70.

[5] Avnir D, Coradin T, Lev O, Livage J. Recent bio-applications of sol-gel materials J Mater Chem 2006;16:1013-30.

[6] Gupta R, Chaudhury NK. Entrapment of biomolecules in sol-gel matrix for applications in biosensors: problems and future prospects. Biosens Bioelectron 2007;22:2387-99.

[7] Reetz MT, Zonta A, Simpelkamp J, Rufinska A, Tesche B. Characterization of hydrophobic sol-gel materials containing entrapped lipases. J Sol-Gel Sci Technol 1996;7:35-45.

[8] Brennan JD, Hartman S, Ilnicki EI, Rakic M. Fluorescence and NMR characterization and biomolecule entrapment studies of sol-gel-derived organicinorganic composite materials formed by sonication of precursors. Chem Mater 1999;11:1853-64

[9] Reetz MT, Wenkel R, Avnir D. Entrapment of lipases in hydrophobic sol-gel materials: efficient heterogeneous biocatalysts in aqueous medium. Synthesis 2000;6:781-3.

[10] Keeling-Tucker T, Rakic M, Spong C, Brennan JD. Controlling the material properties and biological activity of lipase within sol-gel derived bioglasses via organosilane and polymer doping. Chem Mater 2000;12:3695-704.

[11] Badjić JD, Kadnikova EN, Kostić NM. Enantioselective aminolysis of an $\alpha$-chloroester catalyzed by candida cylindracea lipase encapsulated in sol-gel silica glass. Org Lett 2001;3:2025-8.

[12] Noureddini H, Gao X, Joshi S, Wagner PR. Immobilization of pseudomonas cepacia lipase by sol-gel entrapment and its application in the hydrolysis of soybean oil. J Am Oil Chem Soc 2002;79:33-40. 
[13] Reetz MT, Tielmann P, Wiesenhöfer W, Könen W, Zonta A. Second generation sol-gel encapsulated lipases: robust heterogeneous biocatalysts. Adv Synth Catal 2003;345:717-28.

[14] Kunkova G, Szilva J, Hetflejs, Sabata S. Catalysis in organic solvents with lipase immobilized by sol-gel technique. J Sol-Gel Sci Technol 2003;26:1183-7.

[15] El Rassy H, Maury S, Buisson P, Pierre AC. Hydrophobic silica aerogel-lipase biocatalysts. Possible interactions between the enzyme and the gel. J Non-Cryst Solids 2004;350:23-30.

[16] Kim K, Park JK, Kim HK. Preparation of nano-porous silica aerogel and its application to a bio-conversion process. Resour Process 2006;53:3-5.

[17] Soares CMF, dos Santos HF, Itako JE, de Moares FF, Zanin GM. NMR characterization of the role of silane precursors on the catalytic activity of sol-gel encapsulated lipase. J Non-Cryst Solids 2006;352:3469-77.

[18] Noureddini H, Gao X. Characterization of sol-gel immobilized lipases. J SolGel Sci Technol 2007:41:31-41.

[19] Ellis RJ. Macromolecular crowding: an important but neglected aspect of the intracellular environment. Curr Opin Struct Biol 2001;11:114-9.

[20] Minton AP. The influence of macromolecular crowding and macromolecula confinement on biochemical reactions in physiological media. J Biol Chem 2001;276:10577-80.

[21] Perham M, Stagg L, Wittung-Stafshede P. Macromolecular crowding increases structural content of folded proteins. FEBS Lett 2007;581:5065-9.

[22] Eggers DK, Valentine JS. Molecular confinement influences protein structure and enhances thermal protein stability. Protein Sci 2001;10:250-61.

[23] Eggers DK, Valentine JS. Crowding and hydration effects on protein conformation: a study with sol-gel encapsulated proteins. J Mol Biol 2001;314:911-22.

[24] Rocha VA, Eggers DK. Hydrophobic, organically-modified silica gels enhance the secondary structure of encapsulated apomyoglobin. Chem Commun 2007:1266-8.

[25] Edmiston PL, Wambolt CL, Smith MK, Saavedra SS. Spectroscopic characterization of albumin and myoglobin entrapped in bulk sol-gel glasses. J Colloid Interface Sci 1994;163:395-406.

[26] Flora KK, Brennan JD. Effect of matrix aging on the behavior of human serum albumin entrapped in a tetraethyl orthosilicate-derived glass. Chem Mater 2001;13:4170-9.

[27] Fischer T, Hess H. Materials chemistry challenges in the design of hybrid Take down: supporting protein function within artificial environments. J Mater Chem 2007; 17:943-51.

[28] Chiti F, Dobson CM. Protein misfolding, functional amyloid, and human disease. Annu Rev Biochem 2006;75:333-66.

[29] Goodsell DS. The machinery of life. New York: Springer-Verlag; 1998.

[30] Brinker CJ, Scherer GW. Sol-gel science: the physics and chemistry of sol-gel processing. San Diego: Academic Press; 1990.

[31] Nguyen DT, Smit M, Dunn B, Zink JI. Stabilization of creatine kinase encapsulated in silicate sol-gel materials and unusual temperature effects on its activity. Chem Mater 2002;14:4300-6.

[32] Ronda L, Bruno S, Viappiani C, Abbruzzetti S, Mozzarelli A, Lowe KC, et al. Circular dichroism spectroscopy of tertiary and quaternary conformations of human hemoglobin entrapped in wet silica gels. Protein Sci 2006;15: 1961-7.

[33] Greenfield NJ. Using circular dichroism spectra to estimate protein secondary structure. Nat Protocol 2006;1:2876-90.

[34] Schmid FX. Spectral methods of characterizing protein conformation and conformational changes. In: Creigthon TE, editor. Protein structure: a practical approach. New York: IRL Press; 1997. p. 276-85.

[35] Puett D. Conformational studies on a glycosylated bovine pancreatic ribonuclease. J Biol Chem 1973;248:3566-72.

[36] Scherer GW. Effect of drying on properties of silica gel. J Non-Cryst Solids 1997;215:155-68

[37] Deshpande R, Hua DW, Smith DM, Brinker JC. Pore structure evolution in silica gel during aging/drying. III. Effects of surface tension. J Non-Cryst Solids 1992; 144:32-44.

[38] Harreld JH, Dong W, Dunn B. Ambient pressure synthesis of aerogel-like vanadium oxide and molybdenum oxide. Mater Res Bull 1998;33:561-7.

[39] Hwang SW, Jung HH, Hyun SH, Ahn YS. Effective preparation of crack-free silica aerogels via ambient drying. J Sol-Gel Sci Technol 2007;41:139-46.

[40] Sirangelo I, Bismuto E, Tavassi S, Irace G. Near-ultaviolet circular dichroic activity of apomyoglobin: resolution of the individual tryptophanyl contributions by site-directed mutagenesis. Eur Biophys J 1998;27:27-31.

[41] Sing KSW, Everett DH, Haul RAW, Moscou L, Pierotti RA, Rouquerol J, et al. Reporting physisorption data for gas/solid systems with special reference to the determination of surface area and porosity (Recommendations 1984). Pure Appl Chem 1985;57:603-19.
[42] Everett DH, Powl JC. Adsorption in slit-like and cylindrical micropores in the Henry's law region. A model for the microporosity of carbons. J Chem Soc, Faraday Trans 1 1976;72:619-36.

[43] Clifford JS, Legge RL. Use of water to evaluate hydrophobicity of organicallymodified xerogel enzyme supports. Biotechnol Bioeng 2005;92:231-7.

[44] El Rassy H, Pierre AC. NMR and IR spectroscopy of silica aerogels with different hydrophobic characteristics. J Non-Cryst Solids 2005;351:1603-10.

[45] Striova J, Higgins DA, Collinson MM. Phase separation in class II organically modified silicate films as probed by phase-imaging atomic force microscopy. Langmuir 2005;21:6137-41.

[46] Goring GLG, Brennan JD. Effect of ormosil and polymer doping on the morphology of separately and co-hydrolysed silica films formed by a two-step aqueous processing method. Chem Mater 2007;19:5336-46.

[47] Loy DA, Baugher BM, Baugher CR, Schneider DA, Rahimian K. Substituent effects on the sol-gel chemistry of organotrialkoxysilanes. Chem Mater 2000; $12: 3624-32$

[48] Lei C, Shin Y, Liu J, Ackerman EJ. Entrapping enzyme in a functionalized nanoporous support. J Am Chem Soc 2002;124:11242-3.

[49] Lei C, Shin Y, Magnuson JK, Fryxell G, Lasure LL, Elliott DC, et al. Characterization of functionalized nanoporous supports for protein confinement. Nanotechnology 2006; 17:5531-8.

[50] Bottini M, DiVenere A, Lugli P, Rosato N. Conformation and stability of myoglobin in dilute and crowded organically modified media. J Non-Cryst Solids 2004;343:101-8.

[51] Pandey PC, Upadhyay S, Upadhyay BC, Tripathi VS. Studies on new ormosils derived from reactive alkoxysilane precursors as a function of hydrophobicity/hydrophilicity. J Sol-Gel Sci Technol 2005;33:25-32.

[52] Brook MA, Chen Y, Guo K, Zhang Z, Jin W, Deisingh A, et al. Proteins entrapped in silica monoliths prepared from glyceroxysilanes. J Sol-Gel Sci Technol 2004;31:343-8.

[53] Lin T-Y, Wu C-H, Brennan JD. Entrapment of horseradish peroxidase in sugarmodified monoliths: toward the development of a biocatalytic sensor. Biosens Bioelectron 2007;22:1861-7.

[54] Sui X, Cruz-Aguado JA, Chen Y, Zhang Z, Brook MA, Brennan JD. Properties of human serum albumin entrapped in sol-gel-derived silica bearing covalently tethered sugars. Chem Mater 2005;17:1174-82.

[55] Dunker AK, Fernández A. Engineering productive enzyme confinement. Trends Biotechnol 2007;25:189-90.

[56] Simionescu N, Simionescu M, Palade GE. Permeability of muscle capillaries to exogenous myoglobin. J Cell Biol 1973;57:423-52.

[57] Voet D, Voet JG, Pratt CW. Fundamentals of biochemistry. New York: John Wiley and Sons; 2001. p. 168.

[58] Harreld JH, Ebina T, Tsubo N, Stucky G. Manipulation of pore size distribution in silica and ormosil gels dried under ambient pressure conditions. J NonCryst Solids 2002;298:241-51.

[59] Zheng L, Brennan JD. Measurement of intrinsic fluorescence to probe the conformational stability and thermodynamic stability of a single tryptophan protein entrapped in a sol-gel derived glass matrix. Analyst 1998;123:1735-44.

[60] Gottfried DS, Kagan A, Hoffman BM, Friedman JM. Impeded rotation of a protein in a sol-gel matrix. J Phys Chem 1999;103:2803-7.

[61] Chirico G, Cannone F, Beretta S, Diaspro A, Campanini B, Bettati S, et al. Dynamics of green fluorescent protein mutant2 in solution, on spin-coated glasses, and encapsulated in wet silica gels. Protein Sci 2002;11:1152-61.

[62] Hungerford G, Rei A, Ferreira MIC, Suhling K, Tregidgo C. Diffusion in a sol-gelderived medium with a view toward biosensor applications. J Phys Chem B 2007; $111: 3558-62$

[63] Gonnelli M, Strambini GB. Structure and dynamics of proteins encapsulated in silica hydrogels by Trp phosphorescence. Biophys Chem 2003;104:155-69.

[64] Zheng L, Flora K, Brennan JD. Improving the performance of a sol-gel-entrapped metal-binding protein by maximizing protein thermal stability before entrapment. Chem Mater 1998;10:3974-83.

[65] Lan EH, Dave BC, Fukuto JM, Dunn B, Zink JI, Valentine JS. Synthesis of sol-gel encapsulated heme proteins with chemical sensing properties. J Mater Chem 1999;9:45-53.

[66] Badjić JD, Kostić NM. Effects of encapsulation in sol-gel silica glass on esterase activity, conformational stability, and unfolding of bovine carbonic anhydrase II. Chem Mater 1999:11:3671-9.

[67] Bhagat SD, Kim YA, Ahn YS, Yeo JG. Textural properties of ambient pressure dried water-glass based silica aerogel beads: one day synthesis. Micropor Mesopor Mater 2006;96:237-44

[68] Tsai H, Doong R. Preparation and characterization of urease-encapsulated biosensors in poly(vinyl alcohol)-modified silica sol-gel materials. Biosens Bioelectron 2007;23:66-73. 